\title{
Acessibilidade Arquitetônica e Desenho Universal no Mundo e Brasil
}

\author{
Architectural Accessibility and Universal Design in the World and Brazil \\ Accesibilidad Arquitectónica y el Diseño Universal em el Mundo y Brasil
}

\section{Lucas de Souza Ramalhaes Feitosa}

Mestrando em Arquitetura e Urbanismo, Universidade Presbiteriana Mackenzie - UPM, Brasil lucas.feitosa@gmail.com

\section{Roberto Righi}

Professor Doutor em Arquitetura e Urbanismo, Universidade Presbiteriana Mackenzie - UPM, Brasil. roberto.righi@mackenzie.br 

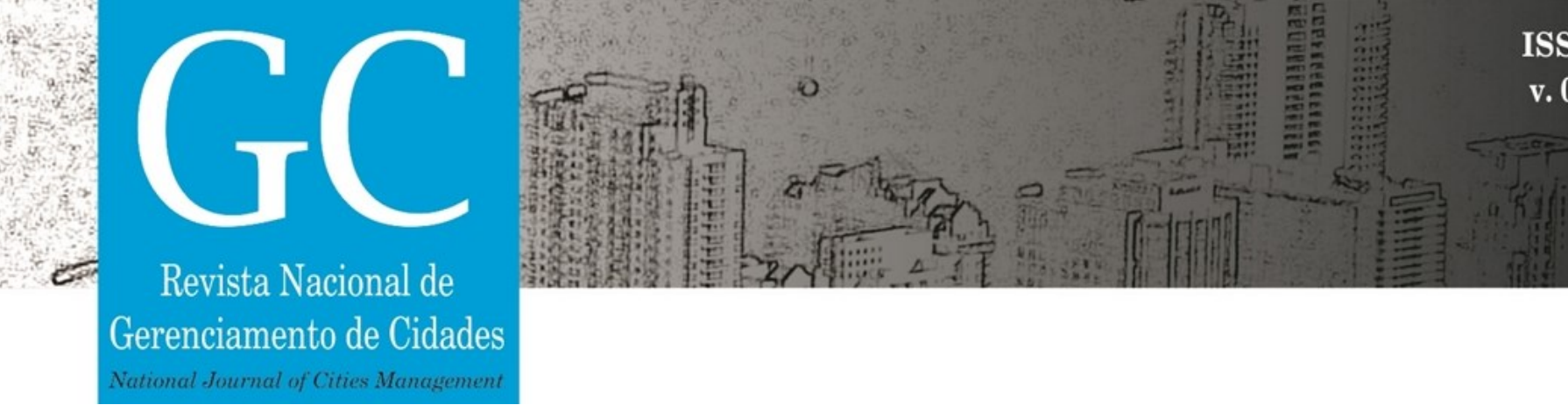

\section{RESUMO}

Este artigo objetiva mostrar o surgimento e desenvolvimento dos conceitos modernos de acessibilidade, desenho universal, acessibilidade no Brasil e mundo, e envolvendo a preocupação com espaços acessíveis e universais para atender as pessoas, possuindo ou não algum tipo de deficiência e as questões para inclusão social. Houve um agravamento na demanda por acessibilidade resultante de um aumento absoluto e relativo do número de pessoas com deficiência no Brasil e mundo, que é abordado neste trabalho.

PALAVRAS-CHAVE: Acessibilidade, Pessoa com Deficiência; Desenho Universal; Inclusão Social, Ergonomia.

\section{ABSTRACT}

This article aims to show the emergence and development of accessibility concepts, universal design, accessibility in Brazil, and involving the concern spaces accessible and universal to meet people, having or not some kind of disability and issues for social inclusion. There was an increase in demand for accessibility resulting from an absolute and relative increase in the number of people with disabilities in Brazil and the world, which is covered in this work

KEYWORDS: Accessibility; Person with Disabilities; Universal Design; Social Inclusion; Ergonomics.

\section{RESUMEN}

Este artículo tiene como objetivo mostrar la aparición y el desarrollo de los conceptos de accesibilidad modernas, el diseño universal, accesibilidad en Brasil y en el mundo, y la participación de los espacios preocupación accesible y universal para conocer gente, tener o no algún tipo de discapacidad y las cuestiones de inclusión social. Hubo un aumento de la demanda de accesibilidad como resultado de un aumento absoluto y relativo en el número de personas con discapacidades en Brasil y en el mundo, que se cubre en este trabajo.

PALAVRAS-CHAVE: Accesibilidad, Persona con Discapacidad, Diseño Universal, La Inclusión Social, Ergonomía. 


\section{INTRODUÇÃO}

A acessibilidade tornou-se relevante após a Segunda Guerra Mundial e mais recentemente, nas Guerras da Coreia, Vietnã e Oriente Médio, traduzindo-se na progressiva mudança de postura dos governos e da Organização das Nações Unidas - ONU, que se sensibilizaram e conscientizaram da necessidade de integração dos militares com sequelas, e dos civis que retornavam mutilados dos conflitos. Esta atitude de inclusão social passou por reconhecimento internacional e nacional de acordo com Leite (2011). Em 1970 a ONU promoveu o "Design Livre de Barreiras", conforme Roosmalen, Ohnabe (2007) e as primeiras diretrizes de acessibilidade passaram a ser generalizados na Europa, Estados Unidos e Japão. Neste período, a acessibilidade, levou em consideração os edifícios, vias públicas e condições de educação e trabalho de acordo com Godinho (2010).

No Brasil, a acessibilidade conforme Leite (2011) teve início em 1981, quando foi declarado o Ano Internacional dos Portadores de Deficiência pela ONU. Neste contexto, surgiu à primeira norma técnica, a NBR 9050:1985 da Associação Brasileira de Normas Técnicas - ABNT.

A Constituição Federal de 1988 estabeleceu marco legal para acessibilidade no artigo 227, que assim se refere: "§ 2ㅇ - A lei disporá sobre normas de construção dos logradouros e dos edifícios de uso público e de fabricação de veículos de transporte coletivo, a fim de garantir acesso adequado às pessoas portadoras de deficiência.".

Antes da Constituição de 1988, este assunto só havia sido abordado na Emenda Constitucional no 12, de 17 de outubro de 1978, que "Assegura aos Deficientes a melhoria de sua condição social e econômica", tratando a respeito somente dos acessos aos edifícios e logradouros.

\section{METODOLOGIA}

A metodologia de pesquisa adotada para o levantamento sobre acessibilidade e desenho universal é feita através de pesquisas de referências técnicas, legislativas e normativas, dentre as mais relevantes: Lei Federal 7.405/1985, Constituição Federal de 1988, Lei Federal 7.853/1989, Lei Federal 10.048/2000, Lei Federal 10.098/2000, Decreto Federal 3.298/1999, Decreto Federal 5.296/2004, Decreto Federal 6.949/2009 e a NBR 9050:2015 da ABTN, que enfoca a origem da acessibilidade e o surgimento do desenho universal no mundo e Brasil.

\section{HISTÓRICO DA ACESSIBILIDADE}

Parte significativa da população mundial, de acordo com Alves, Amoy e Pinto (2007), convivem com algum tipo de deficiência, seja ela mental, física, visual ou auditiva, e isso chamou atenção pública para o problema de inclusão social. Visando assegurar os direitos humanos, conforme 
Santos (2010), as barreiras arquitetônicas existentes passaram a serem incompatíveis com o direito à cidadania das pessoas com deficiência.

A aplicação dos conceitos de acessibilidade na arquitetura e urbanismo, conforme Frieden (2001) são atribuídos aos países escandinavos na década de 1950. Nesta época, na Dinamarca, surgiu o conceito de normalização, de acordo com Akiyama (2005). Para Godinho (2010), estas normalizações são: "medidas que permitem a qualquer pessoa viver de forma confortável, independentemente da idade, sexo, incapacidade, percepção e capacidade para se deslocar."

De acordo com Szu-Yu (2009), em 1960, surgiram especificações de acessibilidade aos edifícios para as pessoas com deficiência, na Inglaterra, nos Estados Unidos em 1968 e na Suécia em 1969, mostrando a sequência de adesões a esta iniciativa.

Em 1968 foi realizado um concurso pela organização "Reabilitation International", órgão consultivo da Organização das Nações Unidas - ONU para assuntos de acessibilidade, segundo Souza (2010). O símbolo de acessibilidade escolhido foi o da dinamarquesa Sussane Koefoed. Ela apresentou o "conhecido logotipo com a pessoa com cadeira de rodas" (figura 01), conforme Santos (2010). O logotipo foi também escolhido para representar o Símbolo Internacional de Acesso - SIA, pela ONU.

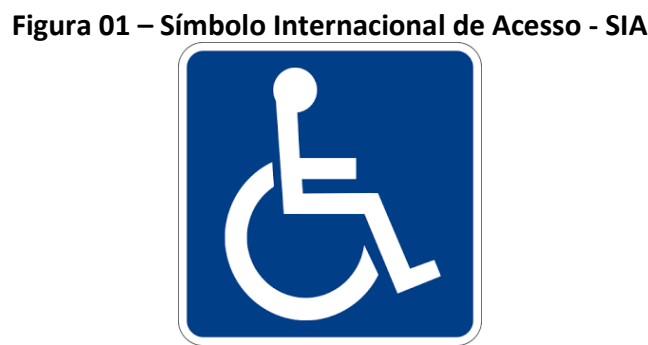

Fonte: http://incluase.blogspot.com.br/2008/10/simbolo-internacional-de-acesso-sai.html, acesso em: 11 fev. 2016.

A ONU em 1970 promoveu o conceito de "Design Livre de Barreiras" e as primeiras diretrizes de acessibilidade para pessoas com deficiências foram publicadas pela Organização Internacional para Padronização (International Organiation for Standardization - ISO). Assim as normas técnicas tornaram-se acessíveis ao público, aprovadas por organismos de normalização, através de consenso de partes interessadas, embasada em resultados da ciência, tecnologia e experiência para obtenção de benefícios a comunidade, conforme observado por Cambiaghi (2011).

De acordo com Alves, Amoy e Pinto (2007), com a aprovação da Declaração dos Direitos das Pessoas com Deficiência Mental de 1971 pela ONU, determinou-se "a necessidade de proteger os direitos dos deficientes físicos e mentais, e de assegurar o seu bem-estar e readaptação". Tornou-se pioneira nos direitos da pessoa com deficiência física e mental, na busca da inclusão social.

Em 1973, nos Estados Unidos, foi criada a "Lei de Reabilitação", que determinava adaptações razoáveis e ambientes com menor restrição no ensino superior e de empregos. As adaptações 
foram financiadas pelo governo federal, através do fornecimento de equipamentos de "Tecnologias de Reabilitação nos Programas Individuais de Reabilitação" de acordo com Godinho (2010). Após dois anos, essas medidas se estenderam para as escolas promovendo a integração das crianças e jovens com deficiência através da "Education for all Handicapped Children Act".

Em 1975, a ONU aprovou a Resolução 3.447 que tratava sobre a Declaração dos Direitos das Pessoas Deficientes, segundo Alves, Amoy e Pinto (2007).

O marco histórico da acessibilidade nos Estados Unidos, segundo Godinho (2010), ocorreu em 1980 com a criação "Americans with Disabilities Act" - ADA, através da "Lei Civil que proíbe a discriminação de pessoas com incapacidade e promove a acessibilidade no trabalho, em edifícios e transportes públicos, em locais que recebem público e nas telecomunicações" e foi sancionada em 1990.

Assim a história da acessibilidade mostra a preocupação com a inclusão das pessoas com deficiência na sociedade, através de eliminação de barreiras arquitetônicas e mudanças de atitudes, como a proibição da discriminação de pessoas com deficiência nos Estados Unidos através da ADA e passam a buscar o "Design Universal" ou "Design para Todos", sendo este último termo usado na Europa e ambos utilizados para atender o maior número possível de pessoas sem a necessidade de adaptação, passando do conceito de acessibilidade.

Nos Estados Unidos em 1982, conforme Moraes (2007), foi publicado um guia de normas mínimas para o desenho acessível. A primeira norma europeia de acessibilidade, só foi publicada em novembro de 1990 pela European Concept for Accessibility Network - EuCan, mas o início de seu desenvolvimento ocorreu em maio de 1985.

A ONU em 1993 publicou as "Normas para Equiparação de Oportunidades para Pessoa com Deficiência" que estabelece para acessibilidade.

De acordo com Godinho (2010) a norma da ONU recomenda aos Estados que sejam previstas condições de acessibilidade em várias áreas sociais, sendo elas: edificações, habitações, transportes públicos e outros meios de transportes, vias públicas e espaços exteriores.

\section{DESENHO UNIVERSAL}

A maneira de desenvolver projetos arquitetônicos, urbanos e de produtos, com desenho universal, teve sua origem nos Estados Unidos, como consequência das mudanças legais, econômicas, demográficas e sociais, envolvendo as pessoas com deficiência e idosos.

É importante salientar que no século XIX a expectativa de vida era baixa e a sociedade norte americana possuía um número reduzido de pessoas com deficiência, mas com os avanços da medicina no século XX, segundo Mello (2013) o quadro foi se alterando com o aumento da expectativa de vida.

O aumento de idosos e pessoas com deficiência refletiu-se diretamente nas legislações dos Estados Unidos entre as décadas de 1970 a 1990. Neste período surgiram leis contra a 
discriminação, conforme abordado no item anterior, tentando assegurar direitos básicos como: educação, emprego, transporte público e a inclusão social.

As barreiras físicas foram identificadas e disto originou uma legislação federal para apontar requisitos mínimos de acessibilidade. De acordo com Mello (2013), os arquitetos ao perceberem que estavam realizando benfeitorias nos ambientes para as pessoas com deficiência, contribuíram também para com os demais usuários e constataram que eles poderiam ser mais vendáveis, seguras e atrativas.

O "Universal Design" ou desenho universal foi utilizado por Ronald L. Mace (Ron Mace), que influenciou a mudança de paradigma dos projetos arquitetônicos e de design. Segundo Cambiaghi (2011), para Mace "o desenho universal é responsável pela criação de ambientes e produtos que podem ser usados pelo maior número de pessoas possível".

A maneira de pensar em projetos para o maior número possível de usuários levou os pesquisadores da Universidade do Estado da Carolina do Norte (North Carolina State University) a aprofundarem suas investigações. Mace fez parte deste grupo de pesquisadores, juntamente com: Bettye Rose Connell, Mike Jones, Jum Mueller, Abir Mullick, Elaine Ostroff, Jon Sanford, Ed Steinfels, Molly Sotry e Gregg Vanderheidenentre, segundo Mello (2013).

Esses pesquisadores propuseram sete princípios e diretrizes para o Desenho Universal, considerados como referências para todos os projetos arquitetônicos, para avaliação de projetos existentes, orientação para projetos de design, literatura de ensino, capacitação de arquitetos, designers, outros profissionais ligados a construção civil, servindo para orientar os consumidores avaliarem produtos e construções, conforme Cambiaghi (2011).

A síntese destes conceitos são expressos através de sete princípios essências.

Comentando e compreendendo melhor estes princípios, pode-se afirmar que o Princípio 1 que trata da Equiparação nas Possibilidades de Uso, os pesquisadores da Universidade da Carolina do Norte, destacam que o desenho universal não é para um grupo especifico de pessoas. De acordo com Mello (2013), ele visa atender a todos os grupos através de uso igualitário e as diretrizes determinam que os objetos, produtos e espaços podem ser utilizados por pessoas com diferentes capacidades.

Para o Princípio 2 que se refere a Flexibilidade de Uso, afirma-se "acomodar uma ampla variedade de preferencias e habilidades individuais" e as diretrizes, visando atender pessoas com diferentes habilidades, diversas preferências e adaptáveis a qualquer uso, conforme Mello (2013).

No Princípio 3 especifica-se sobre o Uso Simples e Intuitivo, que torna o uso "fácil de entender, independente da experiência, conhecimento, habilidades de linguagem ou capacidade de concentração do usuário", de acordo com Mello (2013).

Para Cambiaghi (2011), o Princípio 4 trata da Informação Perceptível, e possui como objetivo, "comunicar eficazmente ao usuário as informações necessárias, independentemente das condições ambientais ou da capacidade sensoriais deste". 
O Princípio 5 refere-se a Tolerância ao Erro, com o objetivo tornar mínimo os riscos e as implicações adversas de ações involuntárias ou acidentais, conforme Mello (2013).

O Princípio 6 trata do Mínimo de Esforço Físico, estabelecendo ao desenho universal a utilização de forma confortável e eficiente, com o mínimo ou baixo esforço físico e de fadiga.

O Princípio 7, para Mello (2013) refere-se ao Dimensionamento de Espaços para Acesso e Uso de Todos os Usuários, estabelecendo que o "tamanho e espaço apropriado para a aproximação, alcance, manipulação e uso, independentemente do tamanho do corpo do usuário, postura ou mobilidade".

Considera-se, assim, que os projetos arquitetônicos feitos de acordo com os sete princípios do Desenho Universal traz benefícios para todos os usuários, tornando as áreas mais seguras, atrativas e vendáveis, conforme constatação dos pesquisadores que os definiram. Desta maneira para que o desenho universal promova a qualidade de vida a todos os cidadãos, nas edificações, cidades, instrumentos e produtos industrializados, conforme Cambiaghi (2011):

“[...] é preciso que haja uma mudança de atitude de todos os agentes sociais envolvidos a saber: usuários, consumidor, empresas, engenheiros, arquitetos, designers e instituições governamentais."

Com esta mudança, cada agente precisa avaliar a importância e aplicação do desenho universal, para todos ganharem com os edifícios, cidades, produtos e principalmente os usuários em relação à universalidade, conforme a NBR 9050:2015 da ABNT.

O objetivo é a criação de ambientes acessíveis para todos, sendo eles, de baixa estatura, cadeirante, deficiente visual, crianças, pessoas com mobilidade temporária ou permanente, entre outros é reforçada por Prado (2010).

O desenho universal deixa de ser apenas uma simples ferramenta de apoio para projeto mais democrático, e torna-se um amplo campo de estudo. No início do século XXI, alcançou no Brasil um grande avanço acadêmico conforme Prado (2010), mas “[...] há necessidade de progresso muito mais amplo para que nos coloquemos em pé de igualdade com países que já debatiam o tema há mais de três décadas."

Os profissionais envolvidos e os materiais necessários para que o desenho universal seja aplicado no desenvolvimento dos projetos e na construção, dependem da formação acadêmica e do setor industrial. Para os profissionais da área da construção civil, como os arquitetos e engenheiros, é pouco disseminada a prática do desenho universal e da edificação acessível no exercício projetual, conforme Ely (2003).

Portanto na utilização do termo desenho universal no desenvolvimento de projetos arquitetônicos, leva-se em consideração a criação de ambientes livres de barreiras físicas, de fácil locomoção e possibilitando a utilização pelo maior número de pessoas. Observando os fatores expostos, imagina-se a repercussão positiva do ganho social, por meio das práticas inclusivas, como o desenho universal, abrirá novos caminhos para mudanças e aceitação dos profissionais que ainda não estão envolvidos e para a indústria. 


\section{ACESSIBILIDADE NO BRASIL}

As questões de acessibilidade no Brasil tornaram-se mais visíveis na década de 1980, pois algumas leis foram promulgadas com intuído de garantir acesso e utilização dos espaços construídos, acompanhando o movimento internacional. A legislação fundamental, de acordo com Silva e Lima (2013), que atende a pessoa com deficiência no Brasil, são elas, a Lei Federal 7.405/1985 e a Lei Federal 7.853/1989 que foi regulamentada através do Decreto Federal 3.298/1999. A Lei Federal 7.405/1985 obriga a colocação do Símbolo Internacional de Acesso SIA, nos locais em que as pessoas com deficiência têm acesso e dá outras providencias.

Em 1988, em resposta aos movimentos organizados por pessoas com deficiências, estabeleceu-se na Constituição Federal, os artigos 50 e 244ㅇq que regulamentam a questão de garantia a acessibilidade nas edificações e transportes, segundo Santos (2010) e que todos são iguais perante a lei.

A Lei Federal 7.853/1989 transfere a responsabilidade aos estados e municípios pela adoção de medidas que eliminem as barreiras de acesso nas edificações, espaços urbanos e transportes para as pessoas com deficiências e o Decreto Federal 3.298/1999 que regulamentou a lei, dispõe sobre a política nacional para a integração da pessoa com deficiência.

Para Silva e Lima (2013) o Ministério Público adquiriu novo papel e referencial com a Constituição Federal de 1988, pois a Lei Federal 7.853/1989 permitiu legitimar a defesa dos direitos das pessoas com deficiência, estabelecendo regras para ação civil pública e inquérito civil.

De acordo com Santos (2010), foi com base nestas leis, decretos e constituição que a justiça deu ganho de causa para algumas ações judiciais importantes para as pessoas com deficiência. Uma destas ações ocorreu contra o Metrô de São Paulo na década de 1980, por não atender as questões referentes à acessibilidade. A empresa possuía uma postura resistente ao assunto e depois das ações judiciais passou a colaborar a favor da normalização técnica. A Secretaria de Estado de São Paulo juntou-se ao Metrô e passaram a colaborar com a Associação Brasileira de Normas Técnicas (ABNT) e o resultado foi a revisão da NBR 9050:1985 da ABNT em 1994. Conforme Santos (2010), a NBR 9050:1994 da ABNT teve como referência significativa "um manual de acessibilidade sem barreiras do estado norte americano de Ohio". No mesmo ano, Edward Steinfield participou de um congresso no Rio de Janeiro de acessibilidade e foi quando incluíram a "universalidade" na norma. Tudo isso gerou alterações importantes que passaram para os projetos arquitetônicos de forma geral, não apenas para um público especifico, como também para as pessoas com deficiência.

A acessibilidade junto às edificações e espaços urbanos no Brasil tornou-se obrigatória após o Decreto Federal 5.296/2004 que regulamentou a Lei Federal 10.048/2000, que "Dá prioridade de atendimento às pessoas que especifica [...]", e a Lei Federal 10.098/2000 que "Estabelece 
normas gerais e critérios básicos para promover a acessibilidade das pessoas portadoras de deficiência ou com mobilidade reduzida e dá outras providências".

O Decreto Federal 5.296/2004 determinou os prazos para aplicação de acessibilidade nas edificações administradas por entidades da administração pública direta ou indireta, sendo até dois de junho de 2007 e para as edificações de uso coletivo existente, até dois de dezembro de 2008 e os demais usos determinados no decreto, o prazo para implantação deveria ser imediata como patrimônio público, edificações de uso multifamiliar e etc.

Outro fato importante para regulamentação de melhoria da acessibilidade é a NBR 9050:2004 da ABNT, que passou a ter efeito de lei através do Decreto Federal 5.296/2004 e Nos últimos 30 anos, como mostra o quadro 2 a NBR 9050 da ABNT, foi revisada três vezes, em 1994, 2004 e 2015.

Quadro 2 - Todas as NBR's 9050 da ABNT.

\begin{tabular}{|c|l|c|c|}
\hline Ano & \multicolumn{1}{|c|}{ Título } & Data de Publicação & Válida a partir de \\
\hline 1985 & $\begin{array}{l}\text { NBR } 9050 \text { - Adequação das edificações e do mobiliário } \\
\text { urbano à pessoa deficiente - Procedimento }\end{array}$ & $01 / 09 / 1985$ & - \\
\hline 1994 & $\begin{array}{l}\text { NBR } 9050 \text { - Acessibilidade de pessoas portadoras de } \\
\text { deficiências a edificações, espaço, mobiliário e } \\
\text { equipamento urbanos - Procedimento }\end{array}$ & $30 / 09 / 1994$ & $31 / 10 / 1994$ \\
\hline 2004 & $\begin{array}{l}\text { NBR } 9050 \text { - Acessibilidade a edificações, mobiliário, } \\
\text { espaços e equipamentos urbanos }\end{array}$ & $31 / 05 / 2004$ & $30 / 06 / 2004$ \\
\hline 2015 & $\begin{array}{l}\text { NBR } 9050 \text { - Acessibilidade a edificações, mobiliário, } \\
\text { espaços e equipamentos urbanos }\end{array}$ & $11 / 09 / 2015$ & $11 / 10 / 2015$ \\
\hline
\end{tabular}

Fonte: realizado pelo autor a partir de ABNT.

Como balanço pode-se considerar que o sucesso da NBR 9050 da ABNT ocorreu como é corroborado por Santos (2010) pela "qualidade técnica, interesse de usuário e da sociedade geral e respaldo de grupos econômicos ou do poder público" e por possuir efeito de lei.

Também é relevante observar que o Brasil ratificou em 2008 a Convenção Internacional sobre os Direitos das Pessoas com Deficiência de 2007, adotada pela ONU e o seu Protocolo Facultativo, através do Decreto Federal 6.949/2009 destinado à melhoria da qualidade de vida, educação, trabalho, saúde, a pessoas com algum tipo de incapacidade, mesmo temporária.

A Convenção prevê o acompanhamento constante na preservação diária dos direitos humanos e que o Brasil mostre a situação atual e "com coragem, reconheça que, apesar do muito que já se fez, ainda há muito que fazer."

Portanto, mesmo possuindo normas, leis e adoção a Convenção Internacional sobre os Direitos das Pessoas com Deficiência, é necessária a aplicação eficaz, com a fiscalização do poder público e da sociedade, pois não adianta possuir uma das mais avançadas legislações senão coloca-las em prática. 


\section{PESSOAS COM DEFICIÊNCIA NO MUNDO E BRASIL}

Em 2011 a Organização Mundial da Saúde (OMS) divulgou que mais de 1 bilhão de pessoas no mundo possuem algum tipo de deficiência. Outra informação divulgada no relatório, foi que poucos países implementaram nos últimos anos, mecanismos eficazes a favor da pessoa com deficiência.

No Brasil, de acordo com o Censo Demográfico de 2010 do Instituto Brasileiro de Geografia e Estatística - IBGE, o número de pessoas com alguma deficiência aumentou muito, comparado ao Censo de 2000. O percentual de pessoas que declaram possuir algum tipo de deficiência no Censo de 2010 é de $23,9 \%$ contra $14,5 \%$ do realizado em 2000, registrando forte aumento de pessoas que se consideram com algum tipo de deficiência. Este aumento considerável no número de pessoas com deficiência, ocorreu em parte pela mudança na metodologia de pesquisa. O Brasil em 2005 passou a fazer parte do Grupo de Washington sobre Estatísticas das Pessoas com Deficiência (Washington Group on Disability Statistics - GW,), que tem como objetivo padronizar o levantamento das estatísticas das pessoas com deficiência, tanto nos censos populacionais como em outras pesquisas domiciliares, seguindo padrões internacionais de estatísticas para obter informações harmonizadas entre os países membros do grupo. Esta homogeneidade na determinação deste índice atrapalhou a sequência de dados nacionais, porem evidenciou uma situação grave, pois o índice de pessoas com deficiência para os Estados Unidos em 2010 é de 19\% (Uniteds States Census Bureau, 2012), apesar das guerras que enfrentou. Continuando, o índice brasileiro é mais que o dobro de países como a Espanha e Alemanha, que possuem 8,5\% (Instituto Nacional de Estadística - INE, 2008) e 9,4\% (Destatis Statistisches Bundesamt, 2013) da população. No continente latino americano, a Argentina e o Chile apresentam 12,9\% (Instituto Nacional Estadística y Censos - INDEC, 2014) e 12,7\% (Ministerio de Desarrolo Social - SENADIS, 2013), respectivamente, ainda muito distantes do Brasil.

A evolução do número de automóveis e motocicletas levaram ao crescimento dos acidentes de trânsito. As mortes e lesões graves são a maioria nos acidentes de motos, segundo médico Alberto Francisco Sabbag, da Associação Brasileira de Medicina do Tráfego - ABRAMET, em reportagem para Amigos Metroviários dos Excepcionais - AME [s.d], pois é considerado um veículo perigoso e exige atenção e equilíbrio do condutor na hora de conduzi-la.

Segundo Sabbag [s.d], anualmente acontecem cerca de 340 mil acidentes com vítimas que sobrevivem e não há nenhuma estatística precisa sobre as pessoas que adquirem algum tipo de deficiência, mas é algo preocupante. Sabbag [s.d] diz que $25 \%$ das pessoas que sofreram acidente de trânsito ficam com sequelas, sendo elas: perda de movimentos, dificuldade de locomoção ou órgãos. Além disto, a violência urbana tem crescido muito em roubos, furtos e assaltos.

Também o envelhecimento da população desempenha um papel relevante nesta estatística. A Organização Mundial da Saúde - OMS (2015) divulgou que até 2050 o Brasil, triplicará o 
Revista Nacional de

Gerenciamento de Cidades

National Journal of Cities Management

número de pessoas com mais de 60 anos e crescendo mais rápido do que a média internacional e envelhecendo mais rápido do que se imagina. Em 2015, o Brasil possui 12,5\% de idosos e deve alcançar os $30 \%$ até meados do século. A classificação da OMS para países com mais de $14 \%$ de idosos, é de "nação envelhecida".

De acordo com Gráfico 1, nota-se um aumento na expectativa de vida, ao longo dos últimos 15 anos.

Gráfico 1 - Esperança de vida ao nascer (em anos) - Brasil - 2000 a 2015.

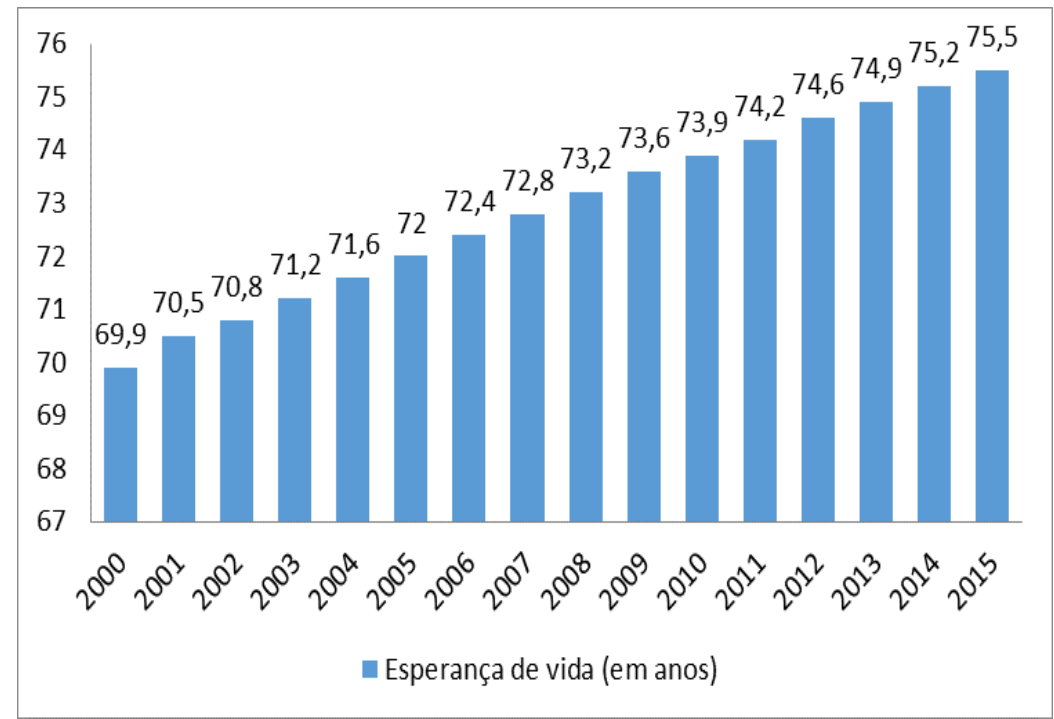

Fonte: IBGE - Projeção da População do Brazil - 2013

Um dos fatores para aumento na expectativa de vida foi pela diminuição da taxa de mortalidade infantil, em 2000 morreram 29 crianças a cada mil nascidas, em 2013 caiu para 15 e estimasse que em 2060 uma queda de 7,1 mortes de acordo com Gráfico 2.

Gráfico 2 - Taxa de Mortalidade Infantil

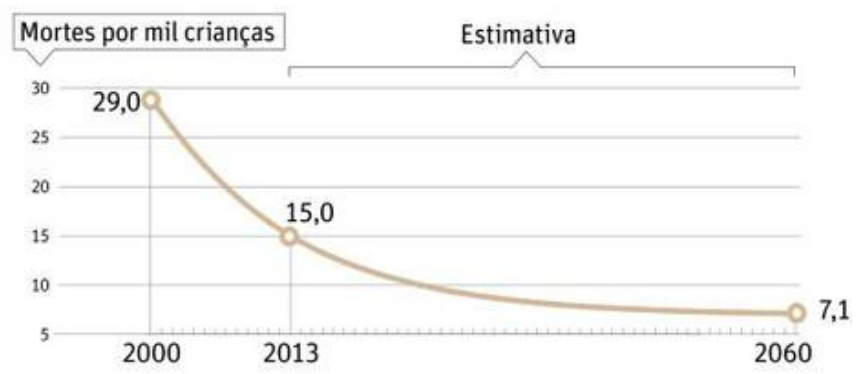

Fonte: https://fernandonogueiracosta.wordpress.com/2010/12/16/piramide-etaria-brasileira/, acesso em: 12 abr. 2016. 
Outro fator para o aumento da expectativa de vida ocorreu com a diminuição da taxa de fecundidade, em 2000 a média de filhos por mulher era de 2,4; em 2013 chegou a 1,8; estimasse 1,5 em 2060 conforme Gráfico 3.

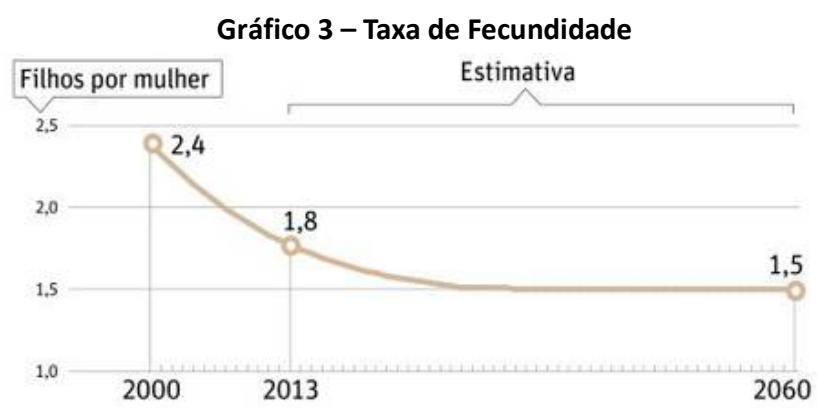

Fonte: https://fernandonogueiracosta.wordpress.com/2010/12/16/piramide-etaria-brasileira/, acesso em: 12 abr.

2016.

As razões para a diminuição da fecundidade ocorreu pela mudança do papel da mulher na sociedade, maior inserção no mercado de trabalho, aumento da escolaridade e planejamento familiar.

O Brasil de 1960 possuía o mesmo perfil do continente africano de 2005, muitos jovens e crianças de acordo com Gráfico 4.

Gráfico 4 - Pirâmide Etária Relativa - África (2005) e Brasil (1960)

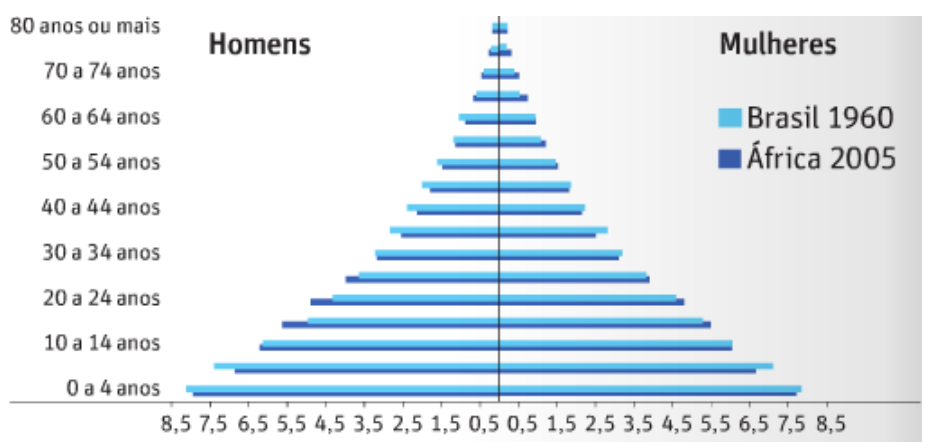

Fonte: https://fernandonogueiracosta.wordpress.com/2010/12/16/piramide-etaria-brasileira/, acesso em: 12 abr. 2016.

O Gráfico 5 mostra a mudança da população brasileira em 2013 comparado a 1960, mostrando uma baixa fecundidade na base da pirâmide em 2013 e projeções para 2040 e 2060, estimasse que mais de um quarto da população tenha mais de 65 anos de acordo com o IBGE. 

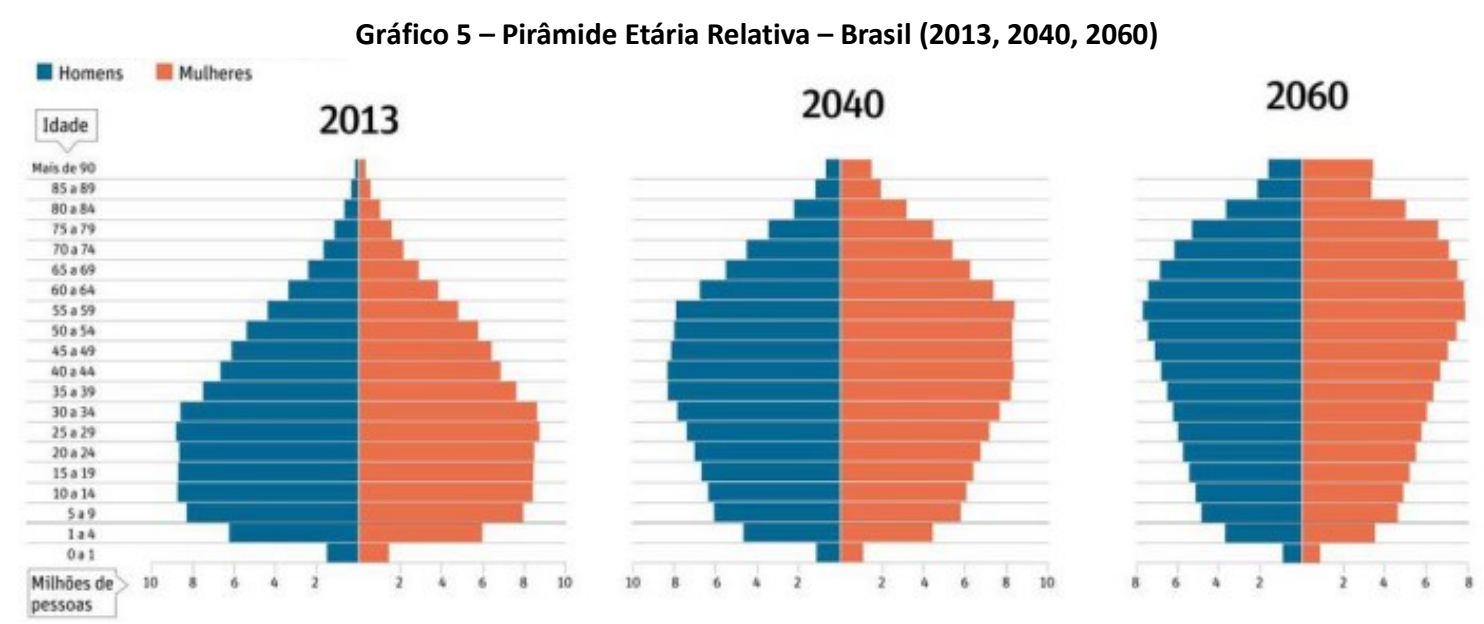

Fonte: https://fernandonogueiracosta.wordpress.com/2010/12/16/piramide-etaria-brasileira/, acesso em: 12 abr. 2016.

Portanto, todas as estatísticas sobre pessoas com deficiência, apresentadas e o envelhecimento da população brasileira, mostram o quanto às questões de acessibilidade e desenho universal devem ser privilegiado no mundo. As práticas de inclusão social através de adaptações de edifícios, cidades e principalmente a integração das pessoas com deficiência e idosos é "...atributo imprescindível a uma sociedade que quer ser mais inclusiva...". Cambiaghi et al. (2011. p.35).

\section{CONSIDERAÇÕES FINAIS}

Parte da população mundial possui algum tipo de deficiência e, além disto, estão sujeitas a algum tipo de discriminação, exclusão social e alguns casos, descaso do poder público. Há o surgimento dos conceitos modernos de acessibilidade a partir do pós-guerra, a busca pela eliminação de barreiras arquitetônicas, a preocupação com o desenho universal que visa atender o maior número de pessoas, independente de limitações físicas ou não.

As guerras trouxeram para os governantes e para a ONU a existência dos problemas das pessoas com deficiências e que passou a ter relevância para inclusão social. As pessoas com deficiências necessitam de espaços livres de barreiras arquitetônicas para exercerem suas atividades e ao longo dos anos e houve um enriquecimento em relação ao conhecimento sobre a acessibilidade.

Os dados mostraram a crescente quantidade de pessoas com deficiências em diversos países e o envelhecimento da população no Brasil. Apesar da existência de convenções internacionais da ONU, que garantem os direitos das pessoas com deficiência e que são adotadas por diversos países, tem muito que se fazer, como no caso do Brasil.

No Brasil, existem normas e legislações, consideradas as mais avançadas no mundo, mas ainda falta aplica-las de forma plena e satisfatória para promover a inclusão social da pessoa com deficiência. Acessibilidade e o desenho universal são direitos fundamentais para as pessoas 
com ou sem deficiência, que asseguram a capacidade de circular pelos espaços com autonomia. Os espaços acessíveis devem ser valorizados pela sociedade, que deve passar a questionar quais as políticas públicas e privadas adotadas no Brasil e no mundo referente à acessibilidade de forma a aperfeiçoa-las e torna-las mais eficazes nas edificações e cidades.

\section{AGRADECIMENTO}

Agradecemos ao XII Fórum Ambiental da Alta Paulista da Estância Turística de Tupã pela oportunidade de participarmos do evento e a Universidade Presbiteriana Mackenzie-UPM.

\section{REFERÊNCIAS BIBLIOGRÁFICAS}

AKIYAMA, Tetsuo. "Japan's Transportation Policies for the Elderly and Disabled" in Workshop on Implementing Sustainable Urban Travel Policies in Japan and other Asia-Pacific countries. Tokyo: [s.n.],2005. Disponível em: <http://www.internationaltransportforum.org/europe/ecmt/urban/Tokyo05/Akiyama.pdf>. Acesso em: 21 . fev. 2016.

ALVES, L. C.; AMOY, R. A.; PINTO, R. L., A questão da acessibilidade das pessoas portadoras de deficiência e a atuação do Ministério Público Estadual na cidade de Campos dos Goytacazes/RJ. In: Revista da Faculdade de Direito de Campos, ano VIII, n. 10, jun. 2007. Disponível em: < http://fdc.br/Arquivos/Mestrado/Revistas/Revista10/Discente/LeandroCausin.pdf>. Acesso em: 4 abr. 2016.

AME. Acidentes de trânsito podem elevar índices de deficiência. Disponível em: <http://www.amesp.org.br/noticias/jornal/novas/tejornal94.shtml>. Acesso em: 22 mar. 2013.

ASSOCIAÇÃO BRASILEIRA DE NORMAS TÉCNICAS. NBR 9050: Adequação das edificações e do mobiliário urbano à pessoa deficiente - Procedimento. Rio de Janeiro, 1985. $37 \mathrm{p}$.

ASSOCIAÇÃO BRASILEIRA DE NORMAS TÉCNICAS. NBR 9050: Acessibilidade de pessoas portadoras de deficiência a edificações, espaços, mobiliários e equipamento urbanos - Procedimento. 1 ed. Rio de Janeiro, 1994. 56 p.

ASSOCIAÇÃO BRASILEIRA DE NORMAS TÉCNICAS. NBR 9050: Acessibilidade a edificações, mobiliário, espaços e equipamentos urbanos. 2 ed. Rio de Janeiro, 2004. $97 \mathrm{p}$.

ASSOCIAÇÃO BRASILEIRA DE NORMAS TÉCNICAS. NBR 9050: Acessibilidade a edificações, mobiliário, espaços e equipamentos urbanos. 3 ed. Rio de Janeiro, 2015. 148 p.

BRASIL. Constituição (1967). Emenda Constitucional no 12, de 17 de outubro de 1978. Assegura aos Deficientes a melhoria de sua condição social e econômica. Diário Oficial [da] República Federativa do Brasil, Brasília, DF, 19 out. 1978. Disponível em: <http://www.planalto.gov.br/ccivil_03/Constituicao/Emendas/Emc_anterior1988/emc1278.htm>. Acesso em: 4 abr. 2016.

BRASIL. Constituição (1988). Constituição da República Federativa do Brasil, de 5 de outubro de 1988. Diário Oficial [da] República Federativa do Brasil, Brasília, DF, 06 out. 1988. Disponível em: <http://www.planalto.gov.br/ccivil_03/constituicao/ConstituicaoCompilado.htm>. Acesso em: 25 de jan. 2016.

BRASIL. Decreto no 3.298, de 20 de Dezembro de 1999. Regulamenta a Lei no 7.853, de 24 de outubro de 1989, dispõe sobre a Política Nacional para a Integração da Pessoa Portadora de Deficiência, consolida as normas de 
proteção, e dá outras providências. Diário Oficial [da] República Federativa do Brasil, Brasília, DF, 21 dez. 1999. Disponível em: <http://www.planalto.gov.br/ccivil_03/decreto/d3298.htm>. Acesso em: 28 mar. 2016.

BRASIL. Decreto no 5.296, de 2 de Dezembro de 2004. Regulamenta as Leis nos 10.048, de 8 de novembro de 2000, que dá prioridade de atendimento às pessoas que especifica, e 10.098, de 19 de dezembro de 2000, que estabelece normas gerais e critérios básicos para a promoção da acessibilidade das pessoas portadoras de deficiência ou com mobilidade reduzida, e dá outras providências. Diário Oficial [da] República Federativa do Brasil, Brasília, DF, 3 dez. 2004. Disponível em: <http://www.planalto.gov.br/ccivil_03/_ato2004-2006/2004/decreto/d5296.htm>. Acesso em: 17 mar. 2016.

BRASIL. Lei no 10.048, de 8 de Novembro de 2000. Dá prioridade de atendimento às pessoas que especifica, e dá outras providências. Diário Oficial [da] República Federativa do Brasil, Brasília, DF, 09 nov. 2000. Disponível em: <http://www.planalto.gov.br/ccivil_03/LEIS/L10048.htm>. Acesso em: 15 mar. 2016.

BRASIL. Lei no 10.098, de 19 de Dezembro de 2000. Estabelece normas gerais e critérios básicos para a promoção da acessibilidade das pessoas portadoras de deficiência ou mobilidade reduzida, e dá outras providências. Diário Oficial [da] República Federativa do Brasil, Brasília, DF, 20 dez. 2000. Disponível em: < http://www.planalto.gov.br/ccivil_03/LEIS/L10098.htm>. Acesso em: 15 mar. 2016.

BRASIL. Lei no 7.405, de 12 de Novembro de 1985. Torna obrigatória a colocação do "Símbolo Internacional de Acesso" em todos os locais e serviços que permitam sua utilização por pessoas portadoras de deficiência e dá outras providências. Diário Oficial [da] República Federativa do Brasil, Brasília, DF, 13 nov. 1985. Disponível em: <http://www.planalto.gov.br/ccivil_03/leis/1980-1988/L7405.htm>. Acesso em: 25 mar. 2016.

BRASIL. Lei no 7.853, de 24 de Outubro de 1989. Dispõe sobre o apoio às pessoas portadoras de deficiência, sua integração social, sobre a Coordenadoria Nacional para Integração da Pessoa Portadora de Deficiência - Corde, institui a tutela jurisdicional de interesses coletivos ou difusos dessas pessoas, disciplina a atuação do Ministério Público, define crimes, e dá outras providências. Diário Oficial [da] República Federativa do Brasil, Brasília, DF, 25 out. 1989. Disponível em: <http://www.planalto.gov.br/ccivil_03/LEIS/L7853.htm>. Acesso em: 25 mar. 2016.

CAMBIAGHI, Silvana. Desenho universal: métodos e técnicas para arquitetos e urbanistas. 2o ed. São Paulo: Editora Senac São Paulo, 2011. p 1-285.

CONVENÇÃO SOBRE OS DIREITOS DAS PESSOAS COM DEFICIÊNCIA: Protocolo Facultativo à Convenção sobre os Direitos das Pessoas com Deficiência. Decreto Legislativo no 186, de 09 de julho de 2008: Decreto no 6.949, de 25 de agosto de 2009. 3. ed. Brasília: Secretaria de Direitos Humanos. Secretaria Nacional de Promoção dos Direitos da Pessoa com Deficiência, 2010.

DESTATIS STATISTISCHES BUNDESAMT. Über 10 Millionen behinderte Menschen im Jahr 2013. Disponível em: <https://www.destatis.de/DE/PresseService/Presse/Pressemitteilungen/2015/05/PD15_168_122.html>. Acesso em: 20 fev. 2016.

ELY, Vera Helena Moro Bins. Ergonomia + Arquitetura: buscando um melhor desempenho do ambiente físico. Universidade Federal de Santa Catarina, Santa Catarina, 2003.

EUROPEAN CONCEPT FOR ACCESSIBILITY NETWORK (EUCAN). ECA: European concept for accessibility. Guide Des Norme. Luxemburgo, 2003.

FRIEDEN, Lex. Toward a Barrier Free World for All in EU expert meeting: Toward a Barrier Free Europe for Citizens with Disabilities. Sweden: Linkoping, 2001. Disponível em: <http://www.disabilityworld.org/0708_01/access/barrierfree.shtml> Acesso em: 2 fev. 2016.

GODINHO, F. A. F. B.. Uma Nova Abordagem para a Formação em Engenharia de Reabilitação em Portugal. 209 p. (Doutorado em Engenharia de Reabilitação) - Universidade de Trás-os-Montes e Alto Douro, Vila Real, 2010. 
Disponível em: <https://repositorio.utad.pt/bitstream/10348/572/1/Phd_fafbgodinho.pdf>. Acesso em: 25 jan. 2016.

IBGE. Censo demográfico 2000. Rio de Janeiro: IBGE, 2003.

IBGE. Censo demográfico 2010. Rio de Janeiro: IBGE, 2012.

IBGE. Estatísticas de Gênero. Disponível em: < http://www.ibge.gov.br/apps/snig/v1/notas_metodologicas.html>. Acesso em: 18 fev. 2016.

INSTITUTO NACIONAL DE ESTADíSTICA Y CENSOS. Censo Nacional de Población, Hogares y Viviendas 2010. Censo del Bicentenario. Serie C. Población con dificultad o limitación permanente. - 1a ed. - Ciudad Autónoma de Buenos Aires: Instituto Nacional de Estadística y Censos - INDEC, 2014. Disponivel em: < http://www.indec.mecon.ar/ftp/cuadros/sociedad/PDLP_10_14.pdf>. Acesso em: 21 fev. 2016.

INSTITUTO NACIONAL DE ESTATÍSTICA. Encuesta de Discapacidad, Autonomía personal y situaciones de Dependencia (EDAD). 2008. Disponivel em: <http://www.ine.es/prensa/np524.pdf>. Acesso em: 20 fev. 2016.

LEITE, Flávia Piva Almeida. A promoção da acessibilidade para as pessoas com deficiência: a observância das normas e do desenho universal. In: Âmbito Jurídico, Rio Grande, XIV, n. 93, out 2011. Disponível em: <http://www.ambitojuridico.com.br/site/?n_link=revista_artigos_leitura\&artigo_id=10604\&revista_caderno=9>. Acesso em: 02 fev. 2016.

MELLO, R. L. Qualidade de Habitação de interesso social: análise a partir da acessibilidade e de desenho universal. Estudo de caso do conjunto residencial Rubens Lara, SP. 2013. 304 p. Dissertação (Mestrado em Arquitetura e Urbanismo) - Universidade Presbiteriana Mackenzie, São Paulo, 2013.

MORAES, M. C. Acessibilidade no Brasil: análise da NBR 9050. 2007. 175 p. Dissertação (Mestrado em Arquitetura e Urbanismo) - Universidade Federal de Santa Catarina, Florianópolis, 2007.

OMS. Relatório Mundial de Envelhecimento e Saúde, 2015. Disponível em: <http://sbgg.org.br/wpcontent/uploads/2015/10/OMS-ENVELHECIMENTO-2015-port.pdf>. Acesso em: 10 jan. 2016.

OMS. Relatório Mundial sobre a Deficiência, 2011. São Paulo: Secretaria dos Direitos da Pessoa com Deficiência, 2012. Disponível em:

http://www.pessoacomdeficiencia.sp.gov.br/usr/share/documents/RELATORIO_MUNDIAL_COMPLETO.pdf>. Acesso em: 4 abr. 2016.

ONU. Assembleia Geral das Nações Unidas. Normas para Equiparação de Oportunidades para Pessoas com Deficiência no 48/96. Disponível em: <http://www.faders.rs.gov.br/legislacao/6>. Acesso em: 20 abr. 2016.

PRADO, Adriana R. de Almeida; LOPES, Maria Elisabete; ORNSTEIN, Sheila Walbe (Org.). Desenho universal: caminhos da acessibilidade no Brasil. São Paulo: Annablume, 2010. P. 9-17.

ROOSMALEN, Linda; OHNABE, Hisaichi. Universal Design. In: COOPER, Rory; OHNABE, Hisaichi; HOBSON, Douglas. An Introduction to Rehabilitation Engineering. New York: Taylor and Francis, 2007. p. 47-66

SANTOS, Gildo Magalhães Dos. Construindo um itinerário histórico do desenho universal: a normatização nacional e internacional da acessibilidade. In: PRADO, Adriana R. de Almeida; LOPES, Maria Elisabete; ORNSTEIN, Sheila Walbe. Desenho universal: caminhos da acessibilidade no Brasil. São Paulo: Annablume, 2010. p. 35-44. 
